Santing-Winter, L., Eijk, R. van der, Donker, G.A. Even een trommelvlies beoordelen: meerdere valkuilen. Bijblijven: 2011, 27(2), 20-24

\begin{tabular}{|l|l|}
\hline Postprint Version & 1.0 \\
\hline Journal website & $\begin{array}{c}\text { http://vb23.bsl.nl/frontend/index.asp?custom_product_id=0168- } \\
\text { 9428\&product_id=\%7BA9EE6675-58B1-4251-BD27-6FA916BB35DD\%7D }\end{array}$ \\
\hline Pubmed link & \\
\hline DOI & \\
\hline
\end{tabular}

This is a NIVEL certified Post Print, more info at http://www.nivel.eu

\title{
Even een trommelvlies beoordelen: meerdere valkuilen
}

\author{
DRS. L. SANTING-WINTER*, DRS. R. VAN DER EIJK** , DR. G.A. DONKER** \\ * Huisarts in opleiding, gezondheidscentrum De Weide, Hoogeveen en Universitair Medisch Centrum \\ Groningen, disciplinegroep Huisartsgeneeskunde \\ ** Huisartsopleider, gezondheidscentrum De Weide, Hoogeveen
}

\section{INLEIDING}

In de (opleidings)praktijk is diagnostiek, zeker van weinig voorkomende aandoeningen, soms lastig. Er kunnen zich valkuilen voordoen op verschillende vlakken: in de diagnostiek, bijvoorbeeld door weinig ervaring, in de continuïteit, wanneer er meerdere artsen contact met een patiënt hebben, en in de opleidingssituatie. De onderstaande ziektegeschiedenis is een voorbeeld van valkuilen op meerdere fronten. Deze hebben we nader geanalyseerd en we hebben aanbevelingen geformuleerd voor verbetering in praktijkvoering en opleidingssituatie.

\section{ZIEKTEGESCHIEDENIS}

Sandra Meijer, 14 jaar, kwam afgelopen zomer samen met haar moeder bij de huisarts met oorpijn. De probleemlijst van patiënte meldt een adenotonsillectomie in 2000 en het plaatsen van trommelvliesbuisjes in 2000, 2003 en 2005 in verband met recidiverende otitiden. Sandra is in 2006 voor het laatst met een middenoorontsteking bij de huisarts geweest. Bij lichamelijk onderzoek diagnosticeerde de huisarts in opleiding nu een otitis externa en zij behandelde deze met zure oordruppels. Een maand later kreeg Sandra gehoorverlies en was er veel cerumen in beide oren te zien. Het trommelvlies kon daardoor niet worden beoordeeld. De eigen huisarts sprak af eerst een cerumenlavage te doen. Voordat de doktersassistente de cerumenlavage uitvoerde, vroeg zij de waarnemend huisarts erbij in verband met een afwijkend trommelvlies. De huisarts zag Sandra even tussen zijn spreekuur door en zag nog wat wit beslag rond het trommelvlies. Er werd besloten eerst de ontsteking te behandelen met hydrocortison/neomycine/polymyxine-oordruppels en de cerumenlavage uit te stellen.

Een week later kwam Sandra opnieuw bij de doktersassistente voor de cerumenlavage. De assistente zag nog steeds een ontsteking van het trommelvlies en overlegde met weer een andere waarnemende huisarts. Sandra werd geadviseerd om een afspraak te maken op het spreekuur van de huisarts.

In dit geval kwam zij bij de huisarts in opleiding op het spreekuur. Zij vertelde weer haar verhaal, in het bijzijn van haar moeder. Ze gaf aan oorpijn te hebben en gehoorverlies. Sandra's moeder vond dat de klachten lang genoeg geduurd hadden en vroeg om een verwijzing naar de kno-arts. Bij lichamelijk onderzoek werden achter het linker trommelvlies luchtbellen gezien en achter het rechter trommelvlies wit beslag met schilfering in de gehoorgang. Aangezien de huisarts in opleiding nog niet veel ervaring had met het beoordelen van trommelvliezen, vroeg zij de huisartsopleider erbij om het trommelvlies mee te beoordelen. De huisartsopleider onderbrak even zijn spreekuur en beoordeelde het trommelvlies. Op grond van de klachten, die inmiddels al zes weken duurden, het lichamelijke onderzoek en op aandringen van de moeder, werd Sandra tijdens dit vijfde consult verwezen naar de kno-arts. Deze vermoedde een cholesteatoom in het rechteroor. Patiënte onderging een exploratieve tympanotomie rechts en is doorverwezen voor verdere evaluatie naar een kno-arts die gespecialiseerd is in cholesteatoom. Onduidelijk is nog in welke mate Sandra gehoorverlies houdt. 
Santing-Winter, L., Eijk, R. van der, Donker, G.A. Even een trommelvlies beoordelen: meerdere valkuilen. Bijblijven: 2011, 27(2), 20-24

\section{CHOLESTEATOOM}

De incidentie van een cholesteatoom bij kinderen is drie per 100.000 kinderen per jaar en het komt iets meer bij jongens (58\%) dan bij meisjes (42\%) voor. 1 Een cholesteatoom is een laagsgewijs opgebouwde massa van keratine, afkomstig van huidepitheel van het trommelvlies. Het stratum germinativum, de matrix, blijft keratine produceren dat in de nauwe ruimten van middenoor en koepelholte niet weg kan en door druk op de omgeving tot circulatiestoornissen leidt. Een cholesteatoom groeit expansief, veroorzaakt osteolyse en kan tot grote destructie van de omliggende structuren leiden. 2

Er wordt onderscheid gemaakt tussen twee vormen: een congenitaal en een verworven cholesteatoom. Een verworven cholesteatoom kan op drie manieren ontstaan, waarbij dit het meest wordt gezien bij een progressief ingetrokken trommelvlies (figuur 1). De ruimte die ontstaat bij de intrekking vult zich met squameus keratine afkomstig van het huidepitheel; dit kan de structuren in het middenoor vernietigen (figuur 2). Zeldzamer is het ontstaan van een cholesteatoom bij een trommelvliesperforatie. Door de perforatie kan huidepitheel het middenoor bereiken en schade veroorzaken. Tevens - maar dit gebeurt zelden - kan een cholesteatoom ontstaan als complicatie na het plaatsen van trommelvliesbuisjes. 3 Bij de boven beschreven patiënte waren meerdere malen trommelvliesbuisjes geplaatst. Aan $72,4 \%$ van de verworven cholesteatomen gaat een chronische otitis media vooraf. 4 Kinderen met een palatoschisis, craniofaciale anomalieën, syndroom van Down of syndroom van Turner hebben een verhoogd risico op het ontwikkelen van een cholesteatoom.

\section{[FIGUUR 1,2]}

Klachten en symptomen kunnen verschillende vormen aannemen, afhankelijk van de locatie en de omvang van de destructie. Deze kunnen bestaan uit gehoorverlies van het geleidingstype, perceptief of gemengd. Tevens kunnen duizeligheid, perifere nervusfacialisuitval, acute mastoïditis of een acute meningitis voorkomen. Alarmsymptomen die kunnen wijzen op een cholesteatoom zijn:

witte massa achter een intact trommelvlies;

diep ingetrokken trommelvlies met of zonder granulatie en débris;

focale granulatie op het oppervlak van de hamer;

een loopoor dat langer dan twee weken duurt, ondanks behandeling;

gehoorverlies bij een geopereerd oor in het verleden. 3

Bij otoscopie wordt een perforatie in de membraan van Shrapnell of in het achter-bovenkwadrant van het trommelvlies gezien of een ingroei van epitheel in de achterste helft van het trommelvlies, meestal bedekt door één of meer granulaties en poliepen. Aanvullend onderzoek voor diagnostiek kan zijn: audiometrie, CT-scan of een chirurgische exploratie. Goed visueel onderzoek met behulp van de otoscoop is echter het belangrijkst om tijdige verwijzing te realiseren. Hierbij moet het hele trommelvlies uitgebreid beoordeeld worden. Een cholesteatoom moet bijna altijd operatief verwijderd worden. Na een sanerende operatie kan er blijvend gehoorverlies ontstaan. Late herkenning van een cholesteatoom blijkt een veelvoorkomende oorzaak te zijn van blijvend gehoorverlies. 5

\section{DE VALKUILEN}

De diagnostiek van een cholesteatoom is minder eenvoudig dan het lijkt, omdat otitis media veel voorkomt in de huisartsenpraktijk en een cholesteatoom erg zeldzaam is. De diagnose cholesteatoom moet overwogen worden bij gehoorverlies en een voorgeschiedenis van meerdere malen otitis media en het plaatsen van trommelvliesbuisjes, zoals bij deze casus. Maar een cholesteatoom komt zo weinig voor dat de meeste huisartsen geen ervaring hebben in het stellen van de diagnose. De praktijken van beide opleiders tellen gezamenlijk 523 kinderen tot 20 jaar. De kans per jaar dat een kind met cholesteatoom in deze praktijk wordt gevonden, is één kind per 64 praktijkjaren. De kans dat de huisarts in opleiding een cholesteatoom in haar eerste maand van de opleiding vindt, is nog veel kleiner.

Daarnaast is in de praktijkorganisatie op verschillende fronten iets misgegaan. Ten eerste is Sandra in korte tijd gezien door verschillende assistentes en door meerdere artsen, waardoor het beloop van de ontsteking niet goed te beoordelen was voor de arts. Twee waarnemende huisartsen, de eigen huisarts en twee huisartsen in opleiding hebben Sandra gezien in een tijdsbestek van zes weken in vijf contactmomenten. Te veel artsen en te weinig continuïteit. Sandra moest steeds opnieuw haar verhaal doen en de arts had slechts een vergelijking met de beschrijving in het elektronisch medisch dossier van de 
collega. Er kon zich geen niet-pluisgevoel ontwikkelen op grond van de huidige bevindingen in vergelijking met de eigen bevindingen bij een vorig consult.

Een waarnemend huisarts die 'even' tijdens het spreekuur tussendoor een trommelvlies beoordeelt bij een patiënt op het assistentenspreekuur. Zo gaat het vaak in de dagelijkse praktijk, maar vaak zijn de voorgeschiedenis en het verhaal van de patiënt niet bij de beoordelende arts bekend. Dit gold ook voor deze casus, waarin de huisartsopleider erbij werd geroepen tijdens het consult van de huisarts in opleiding. Even meekijken naar het trommelvlies, zonder het besef te hebben dat dit hetzelfde trommelvlies was dat hij ook had beoordeeld toen de doktersassistente hem erbij had geroepen voor de cerumenlavage. 'Even meekijken' is een kwalijke valkuil en een bekende foutenbron. 6 Het spreekuur wordt onderbroken, je wordt gestoord tijdens een consult, er zitten patiënten te wachten in de wachtkamer en je hebt geen flauw idee welke patiënt je voor je hebt.

\section{CONCLUSIE}

Een cholesteatoom komt zelden voor. Bij kinderen drie per 100.000, dus in de beschreven opleidingspraktijk slechts bij één kind in de 64 jaar. De gevolgen van een cholesteatoom op kinderleeftijd kunnen groot zijn. Blijvend gehoorverlies op jonge leeftijd kan invloed hebben op de verdere ontwikkeling en op de beroepskeuze. Vroege herkenning van een cholesteatoom is daarom belangrijk, zodat de kans op blijvend gehoorverlies geminimaliseerd wordt. De contextuele benadering van voorgeschiedenis, anamnese en goed klinisch onderzoek, maar ook van ongerustheid bij de patiënt en/of diens ouders, is daarin doorslaggevend. Discontinuïteit van zorg en 'even' meekijken bij een patiënt die je niet kent, hebben in dit geval voor een beperkt doctor's delay gezorgd, maar meer nog voor onvrede bij de patiënte en haar moeder. Wanneer in deze casus steeds dezelfde huisarts betrokken was geweest, hadden zij zich meer gehoord gevoeld en was hun ongerustheid eerder herkenbaar geweest voor de huisarts. Beide valkuilen hebben betrekking op hoe een huisartsenpraktijk is georganiseerd. Continuïteit van zorg verbetert de kwaliteit van zorg, maar komt door toename van parttime werkende huisartsen en assistentes, schaalvergroting, het gelegenheid bieden voor opleiding en door agendabeperkingen van patiënten meer onder druk. Omdat de trend van parttime werken toe zal nemen en het ook belangrijk is goede opleidingsplaatsen voor huisartsen en assistentes te creëren, is het belangrijk bij de organisatie van een huisartsenpraktijk en zeker ook een opleidingspraktijk te streven naar zo veel mogelijk continuïteit.

Bij het maken van afspraken gaat de voorkeur uit naar de eigen huisarts of diens huisarts in opleiding. Bij hun afwezigheid kan gevraagd worden bij welke andere huisarts of arts in opleiding een patiënt eerder is geweest. Ten aanzien van consultatie van de huisarts(opleider) door assistente of huisarts in opleiding geldt het belang van continuïteit eveneens. Bekend zijn met de patiënt en diens problematiek is voor de geconsulteerde een voordeel. Daarbij is het goed te beseffen dat 'even kijken' niet kan. Een telefonische consultatie van de opleider kan nuttig zijn als de huisarts in opleiding zich competent voelt bij het klinisch onderzoek. Als dat niet zo is, moet de opleider tijd uittrekken voor een volwaardig consult, waarbij aandacht is voor voorgeschiedenis, anamnese, klinisch onderzoek en ongerustheid bij patiënt en/of diens ouders.

\section{LITERATUUR}

1. Tos M. Incidence, etiology and pathogenesis of cholesteatoma in children. Adv Otorhinolaryngol 1988;40:110-7.

2. Huizing EH, Snow GB. Leerboek keel-, neus- en oorheelkunde. Houten: Bohn Stafleu van Loghum, 2005.

3. Isaacson G. Diagnosis of pediatric cholesteatoma. Pediatrics 2007;120:603-8.

4. Kemppainen HO, Puhakka HJ, Laippala PJ, Sipilä MM, Manninen MP, Karma PH. Epidemiology and aetiology of middle ear cholesteatoma. Acta Otolaryngol 1999;119:568-72.

5. Greenberg JS, Manolidis S. High incidence of complications encountered in chronic otitis media surgery in a U.S. metropolitan public hospital. Otolaryngol Head Surg 2001;125:623-7.

6. Conradi M. Fouten van huisartsen. Amsterdam: Boom, 1995. 
Santing-Winter, L., Eijk, R. van der, Donker, G.A. Even een trommelvlies beoordelen: meerdere valkuilen. Bijblijven: 2011, 27(2), 20-24

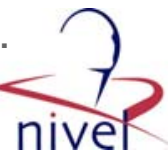

\section{FIGUREN}
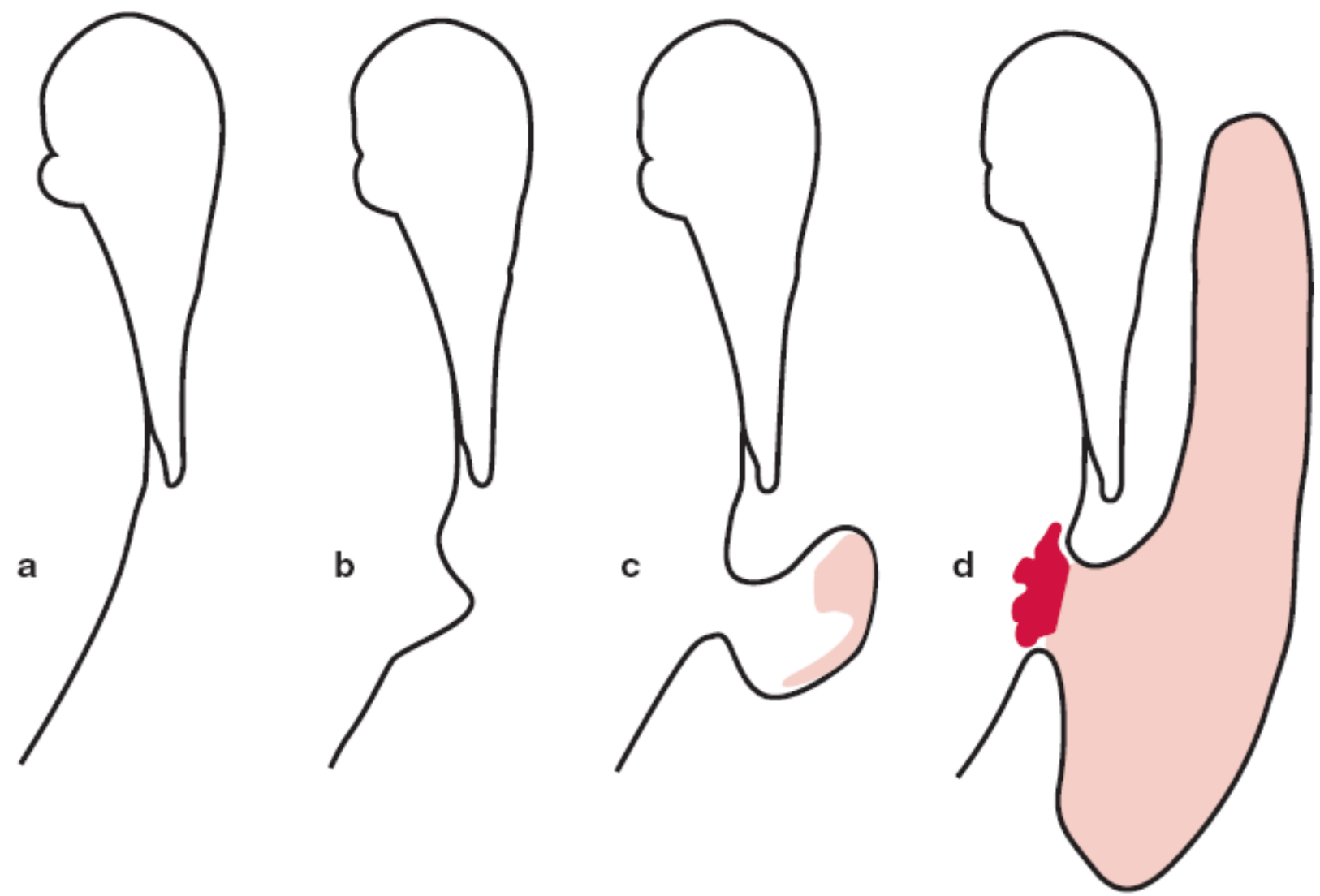

Figuur 1

Trommelvlies wordt progressief ingetrokken. Er ontstaat een ruimte die zich vult met squameus keratine afkomstig van het huidepitheel dat de structuren in het middenoor kan vernietigen. 
Santing-Winter, L., Eijk, R. van der, Donker, G.A. Even een trommelvlies beoordelen: meerdere valkuilen. Bijblijven: 2011, 27(2), 20-24
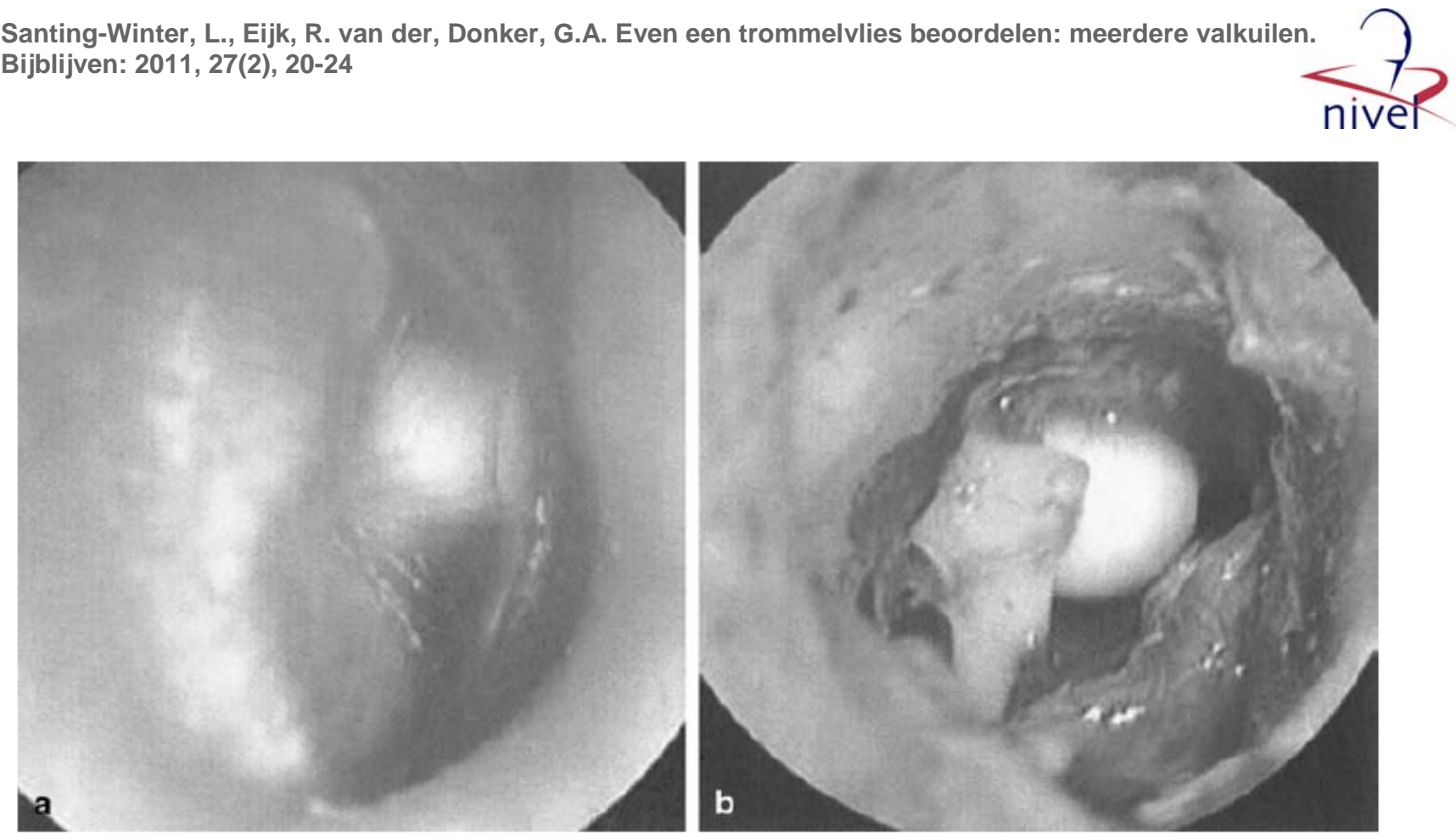

Figuur 2

Cholesteatoom. a: Cholesteatoom in het begin van ontstaan. Subtiele verkleuring van het trommelvlies bij een intact trommelvlies. b: Trommelvliesperforatie met zicht op gehoorbeenderen en granulatie.

Bron: Isaacson 2007 . 